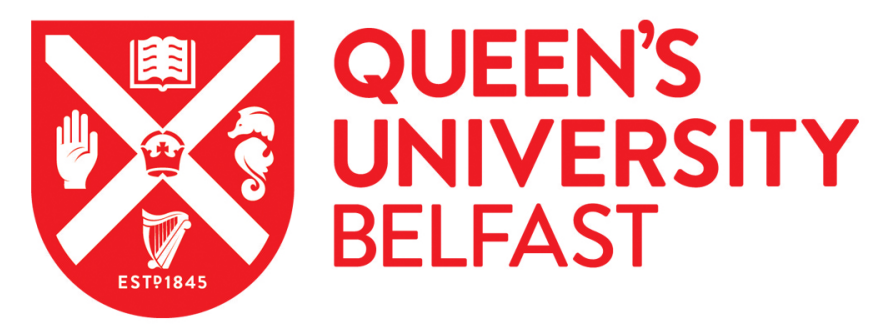

\title{
Achilles tendon rupture - a diagnosis not to be missed
}

Rooney, D., \& Heron, N. (Accepted/In press). Achilles tendon rupture - a diagnosis not to be missed. InnovAiT: Education and inspiration for general practice.

Published in:

InnovAiT: Education and inspiration for general practice

Document Version:

Peer reviewed version

Queen's University Belfast - Research Portal:

Link to publication record in Queen's University Belfast Research Portal

\section{Publisher rights}

Copyright 2020 the Authors.

This manuscript is distributed under a Creative Commons Attribution-NonCommercial-NoDerivs License

(https://creativecommons.org/licenses/by-nc-nd/4.0/), which permits distribution and reproduction for non-commercial purposes, provided the author and source are cited.

\section{General rights}

Copyright for the publications made accessible via the Queen's University Belfast Research Portal is retained by the author(s) and / or other copyright owners and it is a condition of accessing these publications that users recognise and abide by the legal requirements associated with these rights.

Take down policy

The Research Portal is Queen's institutional repository that provides access to Queen's research output. Every effort has been made to ensure that content in the Research Portal does not infringe any person's rights, or applicable UK laws. If you discover content in the Research Portal that you believe breaches copyright or violates any law, please contact openaccess@qub.ac.uk. 


\section{Achilles tendon rupture - a diagnosis not to be missed}

The Achilles tendon (AT) is the largest tendon in the human body, connecting the gastrocnemius, soleus and plantaris muscles to the calcaneus. Together with these muscles, the AT causes plantarflexion of the foot at the ankle joint and flexion at the knee, which are vital functions within the gait cycle. The AT also prevents excessive dorsiflexion of the foot. Whilst AT rupture presentations are more commonly seen in the emergency department, it is still frequently seen in general practice, particularly delayed presentations and missed diagnoses. This is anticipated to increase further, especially following the recent COVID-19 pandemic and as people return to sport following a lengthy lay-off. Despite an awareness of the seriousness of this injury, many clinicians are unaware of how it presents and how best to manage the patient. This article will focus on the aetiology of AT ruptures, as well as explaining how they present to general practice and how best to examine the patient clinically suspected to have sustained this injury.

\section{Clinical case scenario}

Henrik, a 28-year-old male attends your clinic on a Monday morning. He states that he has sustained an injury whilst playing competitive football the day before. It was his first game since his league was restarted following a period of inactivity due to the Covid-19 pandemic. Henrik states that he experienced an intense pain at the back of his leg when jumping for a ball. He described the pain as being similar to that experienced when kicked on the back of the leg. He was unable to continue playing and limped off. Due to fears surrounding coronavirus, Henrik failed to attend the emergency department following the match. He asks if you will examine his leg and offer a potential diagnosis. He is unsure of when he can expect to return to sport and would like advice on the best way to manage his injury.

\section{How common are AT ruptures and in whom are they more likely?}

AT ruptures are a common tendon injury, with reported incidence rates ranging between 7 and 40 per 100,000 person-years (Lemme et al., 2018, Clayton and Court-Brown, 2008, Huttunen et al., 2014). Whilst the aetiology of AT ruptures is multifactorial, there are a number of risk factors that have been identified (Box 1).

\section{How do these patients present in GP?}

The presentation may vary, but likely follows rapid plantarflexion with the affected limb's knee extended or following an unexpected/violent ankle dorsiflexion of a plantar-flexed foot. The patient may describe the onset of injury is the point when they "push-off" from a standing start. In the older population, AT rupture may occur without such an obvious trigger, during activities of daily living (Kannus and Jozsa, 1991). At the point of injury, an audible pop may be heard. This is usually followed with intense pain in the midportion of the AT. Historically, patients have been known to compare this sensation to being kicked on the back of the leg. This immediate pain gradually dissipates over time and is followed by a difficulty in walking (due to the inability to plantarflex) (Gross and Nunley, 2016). There may be swelling around the heel or ankle and evidence of bruising around the AT.

\section{How do I examine these patients in GP?}


Inspection

Bruising and swelling may be present around the AT, as shown in figure 1. There may be a loss of the normal resting posture of the AT whilst the patient is lying prone with knees flexed to 90 degrees. In comparison to the non-affected limb, there may be loss of normal plantar flexion in the injured limb.

\section{Figure 1}

\section{Palpation}

There may be tenderness on palpation of the AT, however, this structure is often uncomfortable to palpate. A palpable gap may be present over the posterior calf or in the midportion of the AT.

\section{Movement and functional assessment}

The main deficit to look out for is a weakness of plantarflexion. This will manifest as an inability of the patient to stand on their toes of the affected limb. Sometimes movement is preserved in the ankle, even in the case of a complete AT rupture due to preservation of secondary plantarflexors e.g. the plantaris muscle.

\section{Special tests}

The Thompson test (also known as Simmonds Test) is performed with the patient lying on the examination bed in a prone position, with the legs hanging over the end of the bed or knees flexed to 90 degrees. When the calf is squeezed, you should see slight plantarflexion at the ankle, as shown in figure 2. In the case of an AT rupture, there would be loss of plantar flexion. This is demonstrated in figure 3.

\section{Figure 2 and 3}

\section{What should I do with these patients in GP?}

In general practice, an urgent referral to orthopaedics is vital. Whilst a diagnosis is often clinically based, an ultrasound in this setting may remove any diagnostic uncertainty. However, it can be difficult to distinguish between partial and complete tears using ultrasound, therefore an MRI scan may be required. 


\section{How are these patients managed?}

It is in the secondary care setting that the decision will be made whether the patient requires conservative or surgical management. This decision will be based on the degree of injury and the patient characteristics e.g. age, sporting goals and general physical demands.

Whilst there is still controversy regarding the most effective mode of treatment, the end-goal is the same: to restore length and function of the tendon to its pre-injury state (Gross and Nunley, 2016). Surgical indications for an AT rupture include a defect of $\geq 1 \mathrm{~cm}$ visible on US, late presentation and in athletes wishing to restore pre-injury function as much as possible. The main benefit of surgical management is that it has been shown to result in improved ankle plantarflexion strength when compared to conservative management (Kocher et al., 2002), although this gain is often marginal and may prove detectable only within the setting of elite sport. Another advantage is the apparent lower re-rupture rate following surgery compared to conservative management ( $2 \%$ vs. $4 \%$ ) (Khan et al., 2005).

Advantages of conservative management over surgical treatment are the absence of operative complications, such as infection, adhesion formation and sural nerve injury. Despite the increased risk of re-rupture, conservative management is associated with good outcomes and is a viable option in those patients at greater risk of post-operative complications, e.g. diabetics and patients who smoke.

Surgical treatment options of AT ruptures may include open, limited-open or percutaneous repair (Gross and Nunley, 2016). In contrast to an open repair that involves quite a large incision (around $10 \mathrm{~cm}$ ), a percutaneous repair involves a number of small incisions above and below the tear with the added benefit of being done under local anaesthesia (Metzl et al., 2008). As part of conservative management (and then also post-surgery), a combination of casts and walking boots are used with the foot in different degrees of plantarflexion for generally 12 weeks. This prevents any unnecessary strain on the AT, allowing it to heal.

For positive outcomes long-term, an accelerated physiotherapy-led rehabilitation program is vital (Kocher et al., 2002). Studies have shown that rehabilitation is necessary to improve range of motion in the ankle joint and functional outcomes as well as reducing the chance of re-rupture (Wu et al., 2016).

Following conservative and surgical repair of a ruptured AT, the GP is normally requested to prescribe VTE prophylaxis until the patient is weight-bearing ( $\approx 4$ weeks). Prior to prescribing the VTE prophylaxis, secondary care will usually request routine blood testing to check normal platelet function (via a full blood count) and renal function (via a U\&E).

\section{What complications should the GP look out for following AT rupture?}

The main complication that the GP should be aware of is re-rupture. The risk is approximately $2 \%$ in surgically managed patients and $4 \%$ in conservatively managed patients (Ochen et al., 2019). For surgical patients, there is an increase in other complications such as wound infection, DVT and sural nerve injury, manifesting as altered sensation on the outside of the foot and ankle. Long term complications include reduced range of ankle motion, reduced calf circumference and a lengthened Achilles' tendon, which may in turn require surgical correction. 


\section{Conclusion}

Achilles tendon ruptures are not uncommon in general practice and certainly not a diagnosis to miss. The COVID-19 pandemic has seen drastic increase in the number of cases as reported by practitioners working in sport. As more athletes return to competitive sport without a sufficient preseason, these numbers are anticipated to increase further. Being aware of the risk factors for this injury and the mechanism of injury increases the likelihood of a timely diagnosis. A focused examination is also necessary, looking for loss of plantarflexion of the ankle joint and a positive Thompson test. It's important to remember to not be falsely reassured by maintenance of ankle movements, as secondary plantarflexor muscles may still be intact. It is vital to refer patients with suspected AT ruptures urgently to orthopaedics for further imaging, where a decision will be made on surgical or conservative management. Surgery can be an option for those with a gap between the tendon ends of $>1 \mathrm{~cm}$ and in those physically demanding duties. Despite this, long-term outcomes following conservative and surgical management are similar. Regardless of treatment, all patients will generally be in a combination of casts and boots for up to 12 weeks, before starting a rehabilitation programme in collaboration with a physiotherapist. The GP should be aware of the complications associated with AT ruptures, such as re-rupture, reduced ankle range of motion and calf asymmetry as well as those that occur post-surgery, such as wound infection and DVT.

\section{Key Points}

- Achilles Tendon ruptures are not uncommon and presentations to general practice are likely to increase following a return to sport during the Covid-19 pandemic.

- There are a number of key risk factors that are associated to an increased risk of AT rupture

- AT ruptures usually occur as a result of rapid plantarflexion with the affected limb's knee extended or following an unexpected/violent ankle dorsiflexion of a plantar-flexed foot.

- Thorough examination is vital for an accurate diagnosis of this injury

- If an AT rupture presents to general practice, an urgent referral to orthopaedics is critical

- Individual patient characteristics determine whether a surgical or conservative treatment pathway is followed

\section{References and further information}

CLAYTON, R. A. \& COURT-BROWN, C. M. (2008). The epidemiology of musculoskeletal tendinous and ligamentous injuries. Injury Journal, 39 (12), 1338-44. DOI: 10.1016/j.injury.2008.06.021

GROSS, C. E. \& NUNLEY, J. A. (2016). Acute Achilles tendon ruptures. Foot \& Ankle International, 37 (2), 233-239. DOI: 10.1177/1071100715619606

HUTTUNEN, T. T., KANNUS, P., ROLF, et al. (2014). Acute achilles tendon ruptures: incidence of injury and surgery in Sweden between 2001 and 2012. The American Journal of Sports Medicine, 42 (10), 2419-23. DOI: 10.1177/0363546514540599

KANNUS, P. \& JOZSA, L. (1991). Histopathological changes preceding spontaneous rupture of a tendon. A controlled study of 891 patients. The Journal of bone and joint surgery. American volume, 73 (10), 1507-1525. Retrieved from https://pubmed.ncbi.nlm.nih.gov/1748700/ 
KHAN, R. J., FICK, D., KEOGH, A., CRAWFORD, J., et al. (2005). Treatment of acute Achilles tendon ruptures: a meta-analysis of randomized, controlled trials. Journal of Bone and Joint Surgery, 87 (10), 2202-2210. DOI: 10.2106/JBJS.D.03049

KOCHER, M. S., BISHOP, J., MARSHALL, et al. (2002). Operative versus nonoperative management of acute Achilles tendon rupture: expected-value decision analysis. The American Journal of Sports Medicine, 30 (6), 783-790.

DOI: $10.1177 / 03635465020300060501$

KROLO, I., VISKOVIĆ, K., IKIĆ, D., et al. (2007). The risk of sports activities-the injuries of the Achilles tendon in sportsmen. Collegium Antropologicum, 31 (1), 275-8. Retrieved from https://pubmed.ncbi.nlm.nih.gov/17598413/

LEMME, N. J., LI, N. Y., DEFRODA, S., et al. (2018). Epidemiology of Achilles Tendon Ruptures in the United States: Athletic and Nonathletic Injuries From 2012 to 2016. Orthopaedic Journal of Sports Medicine, 6 (11). DOI: 10.1177/2325967118808238

MAFFULLI N, SHARMA P, LUSCOMBE KL. (2004). Achilles tendinopathy: aetiology and management. Journal of the Royal Society of Medicine, 97(10),472-476. DOI:10.1258/jrsm.97.10.472

METZL, J. A., AHMAD, C. S. \& LEVINE, W. N. (2008). The ruptured Achilles tendon: operative and non-operative treatment options. Current reviews in musculoskeletal medicine, 1 (2), 161-164. DOI: 10.1007/s12178-008-9025-4

MÖLLER, A., ÅSTRÖM, M. \& WESTLIN, N. E. (1996). Increasing incidence of Achilles tendon rupture. Acta Orthopaedica Scandinavica, 67 (5), 479-481. DOI: 10.3109/17453679608996672

OCHEN, Y., BEKS, R. B., VAN HEIJL, M., et al. (2019). Operative treatment versus nonoperative treatment of Achilles tendon ruptures: systematic review and metaanalysis. BMJ, 364. DOI: 10.1136/bmj.k5120

SOLDATIS, J. J., GOODFELLOW, D. B. \& WILBER, J. H. (1997). End-to-end operative repair of Achilles tendon rupture. The American Journal of Sports Medicine, 25 (1), 90-95. DOI: $10.1177 / 036354659702500118$

VAN DER LINDEN, P. D., STURKENBOOM, M. C., HERINGS, et al. (2003). Increased risk of Achilles tendon rupture with quinolone antibacterial use, especially in elderly patients taking oral corticosteroids. Archives of Internal Medicine, 163 (15), 18011807. DOI: 10.1001/archinte.163.15.1801

WU, Y., LIN, L., LI, H.,et al. (2016). Is surgical intervention more effective than non-surgical treatment for acute Achilles tendon rupture? A systematic review of overlapping meta-analyses. International Journal of Surgery, 36 (Pt A), 305-311.

DOI: 10.1016/j.ijsu.2016.11.014

YASUI, Y., TONOGAI, I., ROSENBAUM, A. J., et al. (2017). The Risk of Achilles Tendon Rupture in the Patients with Achilles Tendinopathy: Healthcare Database Analysis in the United States. Biomed Research International, 2017, 7021862. DOI: 10.1155/2017/7021862 
Figure 1. Ruptured left AT with associated swelling

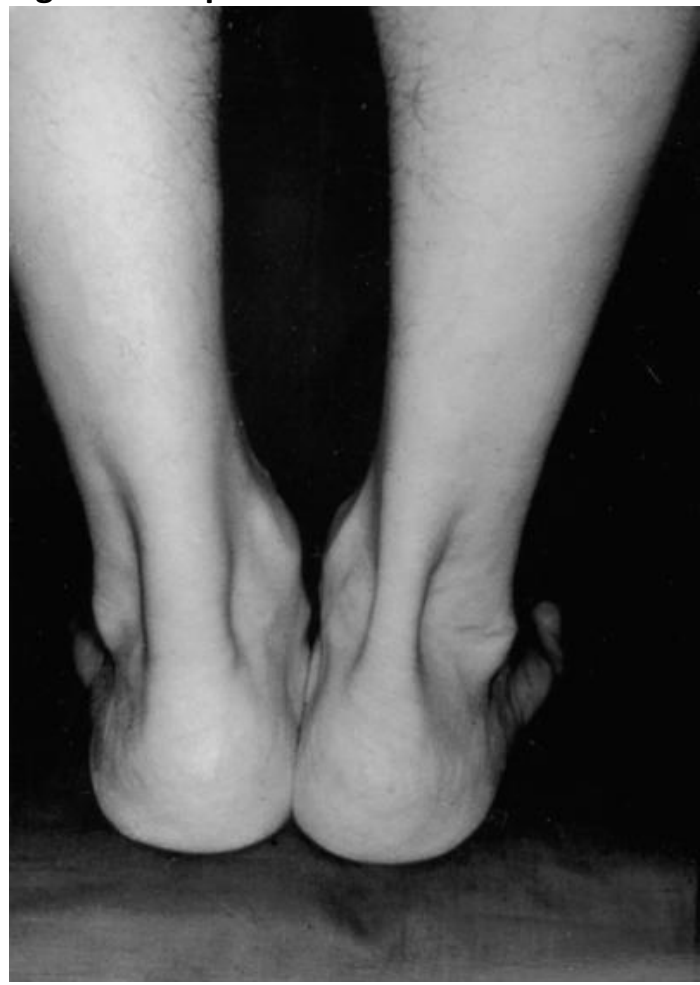

Maffuli, 2004 (Maffulli et al., 2004). https://www.ncbi.nlm.nih.gov/pmc/articles/PMC1079614/

Figure 2. Normal Thomas test with ankle plantarflexion when the calf is squeezed

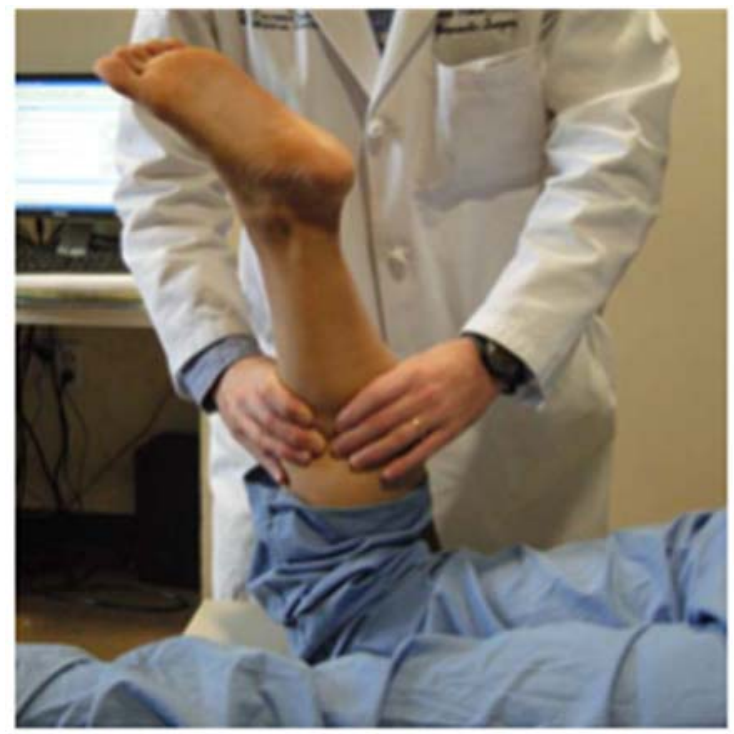

Metzl, 2008 (Metzl et al., 2008). https://link.springer.com/content/pdf/10.1007/s12178-008-90254.pdf 
Figure 1. Abnormal Thomas Test with loss of plantarflexion when the calf is squeezed.

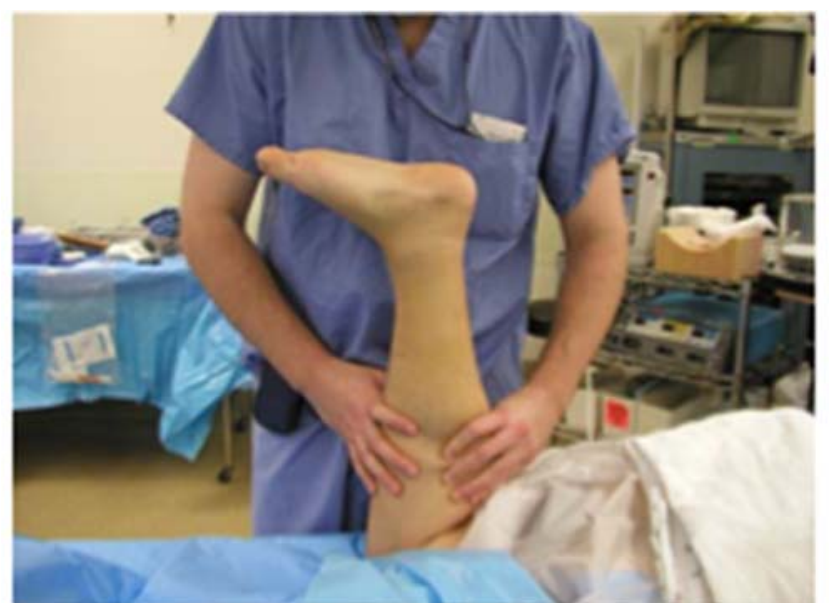

Metzl 2008 (Metzl et al., 2008) https://link.springer.com/content/pdf/10.1007/s12178-008-90254.pdf

Box 1 - Risk Factors for Achilles Tendon Ruptures

- Participation in sport - particularly sports involving rapid changes in speed and jumping e.g. football and racquet sports. Up to 75\% of all AT ruptures occur during sport (Krolo et al., 2007).

- Age - there is a bimodal age distribution of ruptures, most commonly affecting those between the ages of 30-50, with a second peak in patients older than 60 (Möller et al., 1996).

- Gender - AT rupture is 5 times more likely in males than females (Soldatis et al., 1997).

- Quinolone use e.g. ciprofloxacin or levofloxacin (van der Linden et al., 2003).

- History of Achilles tendinopathy or tendonitis e.g. in those with rheumatoid arthritis or gout (Yasui et al., 2017).

- Corticosteroid injections around the AT - may weaken the tendon (van der Linden et al., 2003).

CLAYTON, R. A. \& COURT-BROWN, C. M. 2008. The epidemiology of musculoskeletal tendinous and ligamentous injuries. Injury, 39, 1338-44.

GROSS, C. E. \& NUNLEY, J. A. 2016. Acute Achilles tendon ruptures. Foot \& ankle international, 37, 233-239.

HUTTUNEN, T. T., KANNUS, P., ROLF, C., FELLÄNDER-TSAI, L. \& MATTILA, V. M. 2014. Acute achilles tendon ruptures: incidence of injury and surgery in Sweden between 2001 and 2012. Am J Sports Med, 42, 2419-23.

KANNUS, P. \& JOZSA, L. 1991. Histopathological changes preceding spontaneous rupture of a tendon. A controlled study of 891 patients. The Journal of bone and joint surgery. American volume, 73, 1507-1525.

KHAN, R. J., FICK, D., KEOGH, A., CRAWFORD, J., BRAMMAR, T. \& PARKER, M. 2005. Treatment of acute Achilles tendon ruptures: a meta-analysis of randomized, controlled trials. JBJS, 87, 2202-2210. 
KOCHER, M. S., BISHOP, J., MARSHALL, R., BRIGGS, K. K. \& HAWKINS, R. J. 2002. Operative versus nonoperative management of acute Achilles tendon rupture: expected-value decision analysis. The American journal of sports medicine, 30, 783-790.

KROLO, I., VISKOVIĆ, K., IKIĆ, D., KLARIĆ-CUSTOVIĆ, R., MAROTTI, M. \& CICVARA, T. 2007. The risk of sports activities--the injuries of the Achilles tendon in sportsmen. Coll Antropol, 31, 275-8.

LEMME, N. J., LI, N. Y., DEFRODA, S. F., KLEINER, J. \& OWENS, B. D. 2018. Epidemiology of Achilles Tendon Ruptures in the United States: Athletic and Nonathletic Injuries From 2012 to 2016. Orthop J Sports Med, 6, 2325967118808238.

METZL, J. A., AHMAD, C. S. \& LEVINE, W. N. 2008. The ruptured Achilles tendon: operative and non-operative treatment options. Current reviews in musculoskeletal medicine, 1, 161-164.

MÖLLER, A., ÅSTRÖM, M. \& WESTLIN, N. E. 1996. Increasing incidence of Achilles tendon rupture. Acta orthopaedica Scandinavica, 67, 479-481.

OCHEN, Y., BEKS, R. B., VAN HEIJL, M., HIETBRINK, F., LEENEN, L. P., VAN DER VELDE, D., HENG, M., VAN DER MEIJDEN, O., GROENWOLD, R. H. \& HOUWERT, R. M. 2019. Operative treatment versus nonoperative treatment of Achilles tendon ruptures: systematic review and meta-analysis. bmj, 364.

SOLDATIS, J. J., GOODFELLOW, D. B. \& WILBER, J. H. 1997. End-to-end operative repair of Achilles tendon rupture. The American journal of sports medicine, 25, 90-95.

VAN DER LINDEN, P. D., STURKENBOOM, M. C., HERINGS, R. M., LEUFKENS, H. M., ROWLANDS, S. \& STRICKER, B. H. C. 2003. Increased risk of Achilles tendon rupture with quinolone antibacterial use, especially in elderly patients taking oral corticosteroids. Archives of internal medicine, 163, 1801-1807.

WU, Y., LIN, L., LI, H., ZHAO, Y., LIU, L., JIA, Z., WANG, D., HE, Q. \& RUAN, D. 2016. Is surgical intervention more effective than non-surgical treatment for acute Achilles tendon rupture? A systematic review of overlapping meta-analyses. International Journal of Surgery, 36, 305-311.

YASUI, Y., TONOGAI, I., ROSENBAUM, A. J., SHIMOZONO, Y., KAWANO, H. \& KENNEDY, J. G. 2017. The Risk of Achilles Tendon Rupture in the Patients with Achilles Tendinopathy: Healthcare Database Analysis in the United States. Biomed Res Int, 2017, 7021862. 